Ssciendo Studia Anglica Posnaniensia 55s2 (2020): 495-515

doi: 10.2478/stap-2020-0024

\title{
TWO-SPIRIT IDENTITIES IN CANADA: MAPPING SOVEREIGN EROTIC IN JOSHUA WHITEHEAD'S JONNY APPLESEED
}

\author{
JULIA SIEPAK ${ }^{1}$
}

\begin{abstract}
In colonial times, mapping the New World functioned as an inherent mechanism of exerting colonial domination over Indigenous lands, enacting settler presence on these territories. While the colonial cartographies projected ownership, the non-normative mappings emerging from Aboriginal writing provide an alternative to settler Canadian geography. This article focuses on the imaginative geographies depicted in Joshua Whitehead's Jonny Appleseed (2018), which recounts the story of a young Two-Spirit man who searches for his identity in-between the reserve and the city. The objective of the analysis is to tie the representation of the contemporary queer Indigenous condition with the alternative mappings emerging from Whitehead's novel. In order to address the contemporary Two-Spirit condition in Canada, the article applies current theories proposed by the field of queer Indigenous studies, including the concept of sovereign erotic, which further allows the presentation of the potential of Two-Spirit bodies to transgress colonial cartographies.
\end{abstract}

Keywords: Two-Spirit; Indigiqueer; queer Indigenous studies; Indigenous literature; First Nations literature; sovereign erotic.

During the process of colonization, normative cartography became for the colonists a tool to exert power over the New World. Mapping territories would legitimize colonial presence and the creation of settler colonial nation states. The cartographic representation of space allowed them to conveniently erase Indigenous presence on the seized territories. Moreover, the schematic visual representation of territories emphasized ownership and framed the extractive and industrial practices because, from the settler colonial perspective, the land appeared as a resource meant to be possessed and exploited. Thus, the colonial project necessitated the re-shaping of

1 Nicolaus Copernicus University in Toruń; ul. Bojarskiego 1, 87-100 Toruń, Poland; julia.siepak@doktorant.umk.pl 
territories and re-location of people in a way that would serve its purposes. Mishuana Goeman, in "Mark My Words: Indigenous Women Mapping Our Nations," claims that the European colonial expansion in the Americas did not only include the annexation of Indigenous lands, but also the conquest of Aboriginal, ${ }^{2}$ especially female, bodies:

Colonialism is not just about conquering Native lands through mapping new ownerships, but it is also about the conquest of the bodies, particularly women's bodies through sexual violence, and about recreating gendered relationships. Thus, the making of Indian land into territory required a colonial restructuring of spaces at a variety of scales. (Goeman 2013: 33).

Consequently, territorial conquest intersected with the introduction of settler gender regimes. Goeman further argues that alternative geographies emerging from Indigenous women's writing create liberating and contesting spaces that challenge colonial normative mappings (Goeman 2013: 15). Further, it appears that the colonial heteropatriarchal norms did, although in diverse ways, oppress both Indigenous women and queer-identifying persons in Canada. Thus, taking into consideration the fact that land continues to bear a special importance for Indigenous communities and identities, I would like to extend the reflection on alternative mapping by including queer Indigenous writing. This article traces the imaginative geographies mapped by Joshua Whitehead in his debut novel Jonny Appleseed, tying them to the contemporary queer Indigenous, or Two-Spirit, condition emerging from the narrative.

Two-Spirit, as a concept, was coined in 1990 at the Third International Gathering of American Indian and First Nations Gays and Lesbians in Winnipeg. Since then it has functioned as an umbrella term encompassing the diversity of traditional, as well as contemporary, Indigenous North American gender identities. The concept of TwoSpiritedness aims to bridge the experiences of Indigenous individuals self-identifying as other than heterosexual, and to emphasize their distinct experience from nonNative LGBTQ+ identifying people. Two-Spirit has been embraced mostly by urban Indigenous communities as it bridges diverse Indigenous cultural definitions of a "third gender" or, more generally, different visions of "gender fluidity". Being such a Pan-Indigenous term, Two-Spirit as a concept has also encountered criticism,

2 Throughout the article, I use the terms Indigenous, Aboriginal, and First Nations interchangeably, primarily due to stylistic reasons. According to Gregory Younging's Elements of Style (2018), all of these terms are appropriate to be applied in academic discourse. I am aware of the nuanced meaning that each of them implies, and the different contexts in which these terms are conventionally used, and, therefore, the term Indigenous is being prioritized as the broadest and most inclusive term. For more information concerning terminology in Indigenous studies see Younging (2018) and "Lexicon of Terminology", published by the National Inquiry into Missing and Murdered Indigenous Women and Girls (2019). 
predominantly concerning the issue of being not-culturally specific and having negative associations in certain Indigenous cultures. It is important not to assume that all non-heteronormative Aboriginal individuals will identify themselves as TwoSpirit since some of them identify solely with the concept of a non-binary gender identity present in their original Indigenous culture or choose to identify with a mainstream gender label, such as gay, lesbian, etc. Initially, Two-Spirit was introduced as a term to counter the concept of berdache $e^{3}$, which has been associated in anthropological studies with Indigenous "male sexual deviancy" (Medicine 1997: 148), as well as, further, romanticized to indicate a general sexual laxity of Indigenous peoples. Importantly, the term Two-Spirit shifts the balance of power in knowledge production since Indigenous peoples control the process of defining their gender variation and depart from the uncomfortable concept of berdache proposed by white anthropologists (Driskill et al. 2011: 10-18).

In the introduction to Two-Spirit People, Sue Ellen Jacobs, Wesley Thomas and Sabine Lang (1997: 3) emphasize the significance of queer Indigenous research and its dissemination in order to reconstruct healthy gender relations within contemporary tribal communities and to improve the well-being of representatives of different genders. The process of colonization, with its heteropatriarchal rhetoric, has destabilized the perception on gender identities in Native communities. A Mississauga Nishnaabeg scholar and writer, Leanne Simpson observes that individuals representing gender identities non-conforming to the heteronormative binary have been constantly discriminated against under settler colonial structures:

\begin{abstract}
2SQ [Two-Spirit Queer] bodies and the knowledge and practices those bodies house as Indigenous political orders were seen as an extreme threat to settler society, sovereignty, dispossession, and the project of colonization, colonialism, and assimilation. The powerful relationships queer bodies house - consent, diversity, variance, spiritual power, community, respect, reciprocity, love, attachment—were the very first thing colonizers sought to eliminate, and they began celebrating what they thought was the genocide of $2 \mathrm{SQ}$ people in my nation long before colonization reached nations on the West Coast or in the north (Simpson 2017: 126).
\end{abstract}

This process of eradicating non-conforming gender identities in Indigenous communities as a part of the settler colonial project in North America is approached by Deborah Miranda in terms of gendercide (Miranda 2010: 258-259), which, similarly to colonization, has been a project never successfully finished as Indigenous queer individuals continue to exist. However, the poetics of shame,

The concept of berdache has been used in the field of anthropology to label Indigenous individuals looking or behaving like members of the opposite gender. For more information about the term and its connotations, see Jacobs (1968), Jacobs, Thomas \& Lang (1997), and Morgensen (2011). 
deprivation, and aberration, as well as the heteropatriarchal normativity promoted by settler discourses have greatly influenced contemporary Indigenous gender identities. Current problems on First Nations reserves, such as toxic masculinities and homophobia, may be seen as a direct inheritance of settler colonialism. Consequently, it is important to highlight the efforts to recuperate Indigenous gender diversity and include queer individuals as an integral part of First Nations communities as an act of radical resistance and a part of the decolonial struggle.

The protagonist of Jonny Appleseed identifies as a Two-Spirit character: "an urban NDN [Indian], Two-Spirit femmeboy" (Whitehead 2018: 44), and epitomizes the struggle of contemporary queer Indigenous individuals. Joshua Whitehead's debut novel recounts the story of Jonny's search for identity as a queer young man. The protagonist leaves the reserve, his family, and his first love, Tias, in order to pursue an independent life in the city, where he becomes an online sex worker. The journey back to the reserve to attend the funeral of his mother's partner becomes an emotional itinerary through Jonny's memories. The actual action of coming back home leads the protagonist to self (re)-discovery. Assessing the aspirations of his novel, Whitehead writes that he attempts to show that "Two-Spirit and queer Indigenous folx are not a was, that [they] are not the ethnographic and romanticized notations of revered mystic or shamanic, instead [they] are an is and coming" (Whitehead 2018: 219). Therefore, Jonny Appleseed aims to temporally resist the romanticized anthropological discourse of berdache, as well as to transgress the history of gendercide in order to enact the Indigiqueer present and reimagine Two-Spirit futures.

As argued by Chris Finley, Indigenous Two-Spirit individuals are marginalized within the dominant queer communities and in queer theories (Finley 2011: 33). The novel comments on the double-marginalization of TwoSpirit identities, considering not only the discrimination within the gay movement, but also within their original Aboriginal communities. Jonny reflects on the discrepancy between the queer experience as lived by white Canadians and First Nations individuals on reserves. He desires to share the lifestyles of the characters featured in a mainstream queer TV show:

\footnotetext{
I loved QAF [Queer as Folk]; I wanted to be one of those gay men living their fabulous lives in Pittsburgh. I wanted to live in a loft and go to gay bars and dance with cute boys and fool around in gloryholes. I wanted to work in a comic shop or a university, I wanted to be sexy and rich. I wanted that. (Whitehead 2018: 7).
}

However, the reality on the reserve makes these aspirations seem distant, nearly unattainable. While bewildered by the dominant North American queer discourse present in the mass media, Jonny cannot relate to it: "They told me that they knew what I was going through, that they knew me. How so, I thought? You don't know me. You know lattes and condominiums-you don't know what it's like being a 
brown gay boy on the rez"' (Whitehead 2018: 7-8). The reserve, due to its poor socio-economic situation, emerges then as the main point of division between the dominant and Indigenous experiences of queerness. It designates not only geographical separation from the rest of Canada, but also a lifestyle that does not correspond with its dominant counterpart.

Billy-Ray Belcourt, a Cree poet and scholar, approaches the reserve as a geography of misery in order "to conceptualize the cramped conditions under which life is haphazardly improvised (...) affecting both a corporeal fragility and an intellectual fatigue" (Belcourt 2017: 2). The overwhelming and suffocating character of a reserve as a location, both in a spatial and an ideological sense, conditions Aboriginal lifestyles and verifies their ambitions to sovereignty. The reserve is, therefore, a place where Indigenous people live but where life is not wholly livable, as each day presents a threat to the survival and well-being of an individual, family, and the community at large. On the reserve life is constantly haunted by impending death. Belcourt writes:

\footnotetext{
The reserve, then, is where life is lived at the edge of the world, a bio-necropolitical gulag of sorts where slow death stunts indigeneity's future-bearing potentiality. Put differently, it is an incubator of deadened life, where the plasticity of the life-death binary is worked up so as to harvest bodies that are stripped of vitality and sensation. (Belcourt 2017: 4).
}

The apathy and anguish characterizing the contemporary Indigenous condition is an inheritance of colonial traumas and spatial impositions designed to strip Aboriginal communities of the possibility to flourish. Belcourt argues that the lifestyle lead by First Nations communities on reserves is heavily conditioned by the poor socio-economic situation resulting in complex ways from the processes of settler colonialism.

The instability and impoverishment that Jonny experiences being raised within the geography of misery makes it impossible to bridge his struggle with the lifestyles of mainstream gay men. At the same time, Jonny sees reserve life as evidence of Indigenous survival and proliferation, despite the unfavourable colonial condition:

\footnotetext{
Maybe Nates stay on the rez because they've been pushed so far already. But wherever we end up, we can take pride in knowing that we can survive where no one else can, and that we can make a home out of the smallest of places, and still be able to come home and say, "I love you, Mom". (Whitehead 2018: 196).
}

The life on the reserve is the epitome of colonization and, at the same time, the stage of Vizenorian survivance - survival and resistance despite the colonial domination (Vizenor 2009: 85). Kyle Powys Whyte argues that the contemporary 
Indigenous condition is what Indigenous ancestors would consider a postapocalyptic landscape, suggesting that Indigenous peoples live in the dystopic future today. He supports his claim by directing attention to the fact that environmental degradation and changes in ecosystems distorted the reciprocal relationships that Indigenous people had with their lands, as well as environments, thus impacting and irreversibly altering their lifestyles. In turn, the process of adaptation following the disruption, through recuperating Indigenous relational ecologies, has induced Native people to accommodate new realities (Whyte 2017: 208). In Whitehead's novel, Jonny observes this ability to adapt that let his peoples survive, noting that they "figured out how to live and love in the holy hell of apocalyptic shitstorms" (Whitehead 2018: 194). Despite the history of apocalypse, Indigenous communities thus have not only survived, but also continue to cherish the love that creates potentiality for future generations. In this way, they attempt to transcend settler colonial realities marked by geographies of misery.

Clearly, living on the reserve may be a harsh place to grow up for a young gay man - not only due to the general ambience of reserve life, but also due to strong heteropatriarchal norms of masculinity. The internalized hypermasculine ideal, also called masculindian (McKegney 2014: 1-2), is still the predominant paragon of manliness on reserves. Indigenous men are therefore trapped in "the vicious cycle of toxic Indigenous masculinity [which] is externally imposed on [them] and then internalized and passed on to other men, while at the same time being reinforced by society" (Anderson, Swift \& Innes 2015: 300). This approach to masculinity, based on colonial heteronormativity, conditions homophobia within Indigenous communities. Brendan Hokowithu argues that the dissemination of hypermasculine ideals and homophobia in Indigenous communities would be an answer to the colonial mappings of Indigenous sexuality as effeminate, contrasting to its invader hegemonic heteropatriarchal counterpart (Hokowithu 2015: 85). Thus, the production of the post-contact Indigenous masculinity has been based on the mimicry of paragons of the invader masculinity:

\footnotetext{
one of the symptoms of Indigenous masculinity's mimicry of invader masculinity was the divestment of the feminine out of the masculine. In a Lacanian sense, a masculine subject position was seen to be a rejection of the feminine subject in unconscious terms. The foundation of post-contact Indigenous masculinity, thus, was based upon what Indigenous masculinity was not. Such foundational insecurity has led to ritual displays of physical manliness and hypermasculinity, along with the traditionalization of heterosexuality, homophobia, and patriarchy. (Hokowithu 2015: 88).
}

This mimicry includes the perception of any traces of femininity in men as threatening to the masculinity of the whole group. It is then clear that such a construction of masculinity disadvantages both women and queer men. 
Whitehead's Jonny faces these heteronormative pressures to (over)perform his masculinity in a traditional and ceremonial setting:

\begin{abstract}
It turns out that tradition is an NDN's saving grace, but it's a medicine reserved only for certain members of the reservation, and not for self-ordained Injun glitter princesses like me. This tradition repeats throughout my life: I'm expected to chop wood for ceremonies rather than knead frybread, learn how to hunt with my uncles rather than knit with my aunties, perform the Fancy Feather dance when I really want to do the Jingle Dress dance. "Man up" was the mantra of my childhood and teenage years, because the dick between my legs wasn't enough proof of ownership of NDN manhood. There are a million parts of me that don't add up, a million parts of me that signal immodesty. (Whitehead 2018: 79).
\end{abstract}

The clear division of gender roles in traditional activities and the loss of tasks attributed to the third gender restrict the protagonist to perform male roles, even though he does not feel comfortable with them. The phrase "man up" that haunts Jonny's childhood and adolescence is a sign of the tension that arises between him and his community due to his non-conforming masculinity, and that leads to his feeling of non-belonging and alienation. Settler colonial gender norms internalized on the reserve clearly oppress the protagonist and alienate him from both his community and culture. Jonny comments on his feeling of entrapment and utter marginalization: "there was me, feeling like the only gay NDN in the whole world, voguing and serving face in the basement of a reservation death camp situated in the farthest reaches of this undiscovered continent" (Whitehead 2018: 46).

Further, the violent disciplinary actions of Tias's father illustrate the general masculindian spirit. When Jonny and Tias experiment with painting their nails, Tias's father brutally cuts them, scaring the boy's hands: "We unwound the cloth and looked at his hands. One nail was split wide open, cut straight down to the bed: a bloody, mushy layer that looked like an exposed brain" (Whitehead 2018: 77). This violent act, wounding Tias's body, functions as a corporeal punishment against a queer body, transmitting a message that there is no space for queerness in the household. Tias's father acts in defence of heteronormativity, perceiving the outcome of his action as satisfying rather than horrifying: "“There,' his dad said. 'That looks a hell of a lot more manly.' He threw a dishcloth at Tias and told him to wrap his fingers up, keep pressure on them" (Whitehead 2018: 76). Thus, Tias's father refers to the stereotypes of masculinity that emphasize stamina, toughness, and roughness, excluding expressions of emotionality and experimentation with one's body. The tiniest shred of effeminacy in a male body is punishable since it emerges as a threat to the hegemonic Indigenous masculinity. Therefore, the boys are constrained not to express their queerness on the reserve, and will not receive adequate support from their families or communities in facilitating their coming of 
age as gay men, since they do not comply to hypermasculine heteronormative standards which are taken commonly for granted.

At the same time, a queer Indigenous body is assumed to be deviant, perverted, or even predatory. Early at school, Jonny experiences discrimination from his peers due to his sexuality. Being sexually harassed by a counselor at a Christian youth camp, he is called Jonny Rottenseed and blamed for what has happened: "they were all glaring at me and whispering to each other with disgust and paranoia on their faces. Even at the age of ten, an NDN can become a gay predator, apparently" (Whitehead 2018: 10). The altering of his surname from Appleseed to Rottenseed stresses the corruption and sinfulness posed by Jonny's queer body. The act of sexual abuse committed against Jonny's body is not investigated or considered a crime due to the boy's sexuality and ethnicity. The victim, instead of the perpetrator, is blamed for the abuse. In the same way, the account given by a white man is more credible than that of an Indigenous queer child. This incident sheds light on the precarity of the Two-Spirit condition that will further accompany Jonny throughout his adolescence. He also experiences abuse from his peers on the reserve, and is psychologically and physically bullied. An act of utter humiliation that the boy endures is when a group of boys urinate on him, forcing Tias to do the same (Whitehead 2018: 92). Growing up as a queer boy is for Jonny marked by abuse. As a young man, the protagonist reflects on his experiences, stating: "humility is just humiliation you loved so much it transformed" (Whitehead 2018: 216). Later, Jonny attempts to convert the abuse into growth, yet he is aware of the fact that it will always remain part of his personal geography.

In Jonny Appleseed, leaving the reserve seems the only opportunity to freely express queerness. The urban melting pot is free of the sense of judgement and limitations, which mark the traditional environment. Yet Jonny's decision to leave also meets with criticism on the part of the community. When he moves to Winnipeg, his mother's partner compares him to an apple: "YYou're red on the outside,' he said, 'and white on the inside." (Whitehead 2018: 25). The apple metaphor demonstrates the liminal character of Jonny's identity and stresses the transgression of community values and the boy's alienation. As noticed by June Scudeler, a Métis scholar, it is significant to emphasize that queer Indigenous individuals should be "understood within the complexities of overlapping identities" (Scudeler 2011: 191) rather than in a singularity of experience. Whitehead's protagonist epitomizes these multivocal intersections of urban, Indigenous, Canadian, and queer. Jonny's in-betweenness is haunted by nonbelonging and seclusion. Even though leaving the reserve may prove liberating for the protagonist, he expresses anxiety that marks his departure: "Nobody prepares you for the sting when you're about to leave home. All my life I wanted to leave the rez-and every time I was about to, I stopped myself. It hurt. Leaving 
hurts. It's not glamorous like Julia Roberts makes it seem" (Whitehead 2018: 20). The desire to commence a new life is therefore overshadowed by the feeling of anguish caused by the prospective alienation from his community and family life, from his home.

Nevertheless, Jonny tries to assemble different bits and pieces of his identity in order to feel at home in his body. The protagonist dismisses shame and restores his pride in his queer sexuality and sex work as a profession, reconciliating with the traumatic past of bullying and violence. Yet the cityscape poses new problems and precarities for a queer Indigenous man, including exploitation of his exoticized and stereotyped body. Life in Winnipeg strengthens the sense of liminality of Jonny's experience, who is always entangled in dilemmas and struggles concerning his race and sexuality. In this way, the novel demonstrates that even though the city seems to be a space of liberation, it is also full of restrictions, prejudices, and exploitation. Hence, the protagonist has to negotiate between two different places of (non)belonging to search for what he might call home.

As mentioned before, the protagonist's inner journey is marked by his coming back home to attend the funeral of his stepfather. This process of homecoming is accompanied by the interweaving of stories - unchronological, non-linear, and often unrelated. These vignettes of Jonny's memories constitute an account of his painful history that leads him to embrace his queer identity. Storytelling functions in Whitehead's novel both as a structuring paradigm and a motif that connects the text to the Aboriginal tradition of oral stories. In the narrative the traditional mingles with the actual, contemporary queer experience, creating a mediated space of encounter. The importance of stories in recuperating Indigenous sovereignty, both individual and collective, has been extensively addressed in the field of Indigenous Studies. As stressed by Neal McLeod, a Cree scholar, contemporary Indigenous people search for and find their contemporary identities in the stories (McLeod 2001: 30). Gerald Vizenor in turn bridges two qualities of Indigenous storytelling, survival and resistance, in his influential concept of survivance, which he defines as "continuation of Native stories" (Vizenor 2009: 48). Survivance stresses the potential of storytelling in shaping Indigenous realities and situates stories at the forefront of the decolonial struggle, emphasizing its ability to transcend and subvert settler colonial structures and discourses. The teaching embedded in the stories allows Native cultures to continue. Thus, locating his novel within the Indigenous storytelling tradition, Whitehead inscribes the Two-Spirit struggle within the realm of Aboriginal stories. He makes a point similar to that of Leanne Simpson, who rewrote a traditional Michi Saagiig Nishnaabeg story, conveying a fragment of the community's traditional ecological knowledge, namely, maple syrup production, featuring a gender non-conforming child protagonist. She stresses the importance of the inclusion of stories of all the members of Indigenous communities as an 
integral part of contemporary Aboriginal condition, arguing: "I am repeating this story here deliberately to make the point that it is crucial we tell stories in a way that draws every member of our community into the stories, and to demonstrate the intelligence we all miss when we continue to uphold the colonial gender binary" (Simpson 2017: 145). According to Simpson, voicing the Two-Spirit experience unsettles colonial impositions.

The unsettling and decolonial potential of queer Indigenous storytelling is encapsulated in the concept of sovereign erotic coined by Qwo-Li Driskill. In "Stolen From Our Bodies: First Nations Two-Spirits/Queers and the Journey to a Sovereign Erotic", Driskill defines the concept, referring to its restorative character: "I'm speaking of an erotic wholeness healed and/or healing from the historical trauma that First Nations people continue to survive, rooted within the histories, traditions, and resistance struggles of our nations" (Driskill 2004: 51). According to the Cherokee scholar and poet, the domain of the erotic is not solely sexual but also political since it is able to "disrupt colonial gender regimes that have attempted to disavow and colonize indigenous genders and sexualities" (Driskill et al. 2012: 3). Queer Indigenous bodies carry the political power of subverting colonial heteronormativity and undermining settler policies of gendercide. Two-Spirit histories, survival and thriving indispensably prompt sovereignty. Mark Rifkin emphasizes that the concept of sovereign erotic is "a way of bridging the apparent gap between individual desire, wounding, and longing and collective histories of dispossession, imposition, and removal" (Rifkin 2011: 174). This concept makes it possible to approach the individual and collective histories of colonialism as parallel and congruent. In this perspective, the body emerges as a colonized space. Indigiqueer storytelling is, in turn, a part of sovereign erotic in that it reclaims, reinvents, and reimagines Indigenous TwoSpirit identities both by constituting the voice of the silenced and addressing their experiences (Driskill et al. 2012: 4). Hence, Two-Spirit storytelling is an act of resistance towards the colonial gender limitations and attempts of gendercide and, from a broader perspective, an act of resistance towards settler colonial structures, power relations, and geographical impositions. The poetics of sovereign erotic expresses survivance and, therefore, should be considered a part of the decolonial project. In the words of Driskill, "Two-Spirit people are creating literatures that reflect Sovereign Erotics, and in doing so participate in the process of radical, holistic decolonization" (Driskill 2004: 58).

Storytelling emerges as an important theme of Whitehead's novel since it not only embodies the poetics of sovereign erotic and survivance, but also represents them as a significant foundation of Two-Spirit identities. The only character on the reserve who truly understands Jonny's gender identity is his grandmother. She uses the term Two-Spirit to describe her grandson's gender before the boy is mature enough to define it himself: 


\begin{abstract}
Jonny, m'boy, your kokum old but she ain't dull. You's napêwisk-wewisehot, m'boy, Two-Spirit. You still my beautiful baby grandkid no matter what you want to look like or who you want to like.

I wanted to question her on what she meant by Two-Spirit, but she cut me short by yelling that she had to go, her frybread oil was ready. (Whitehead 2018: 48).
\end{abstract}

This recognition of the attributes characteristic for a traditional Cree gender role that corresponds to the contemporary concept of Two-Spirit in Jonny is present in the teaching transferred by his grandma through storytelling. Her intention is to prepare the boy to fulfill his community role. In this way, gender identity surfaces as inscribed in the stories. It is important to emphasize that in many Indigenous communities representatives of genders different than male and female would carry ceremonial responsibilities, such as making medicine, conducting funerary rites, etc., and they would typically be surrounded by women and be involved in their activities. To honour his identity Jonny's grandma gifts him a pair of beaded earrings (Whitehead 2018: 47) that would typically be a feminine ornament. The careful affection that the protagonist's grandmother displays towards her Two-Spirit grandson resists the masculindian expectations formed by the community. Kokum cherishes Jonny's sexuality, passing down to him stories and traditional knowledge, such as rubbing breath out of a person's belly after their death (Whitehead 2018: 109). She signals that she will supply Jonny with more traditional stories concerning his identity whenever he is ready and asks for it. However, Kokum dies before realizing that promise, which burdens Jonny with the need to self-explore his identity on his own.

This process of Jonny's self-exploration is profoundly centered on bodily pleasure, rendering Whitehead's novel sexually explicit but, simultaneously, subtle and poetic. Daniel Heath Justice observes an unchaining power in corporeality so often deemed taboo by colonial discourses. He writes: "To ignore sex and embodied pleasure in the cause of Indigenous liberation is to ignore one of our greatest resources. It is to deny us one of our most precious gifts. Every orgasm can be an act of decolonization" (Justice 2008: 72). On the same note, Lindsay Nixon notices the shift in Indigenous queer literature that departs from protecting what she calls respectability politics surrounding queer and trans Indigenous bodies, and turns to the unspoiled celebration of sexuality (Belcourt \& Nixon 2018). Jonny is certainly tenacious in his way of enacting his sexual desire and pleasure. Being a sex worker in Winnipeg, he is not embarrassed by his occupation and celebrates it: "It used to bother me, whore, but not so much anymore because, one: I don't sell sex, I sell fantasy and companionship; and two: when they call me what they call me it only helps me to know that I've found a home in my self" (Whitehead 2018: 45). Moreover, Jonny intentionally plays with the stereotypes about Indigenous peoples so as to fulfill his clients' fantasies: 
Pictures and webcam shows are one thing, but let me tell you how tiring it is to create an entire world for clients that fits your body and theirs, and no one else. I can be a barely legal twink for them if they want, but that's going to cost extraand I don't charge them for the ugly memories those fantasies dredge up. Most times, though, they only want me to play NDN. I bought some costumes a few Halloweens ago to help me: Pocasquaw and Chief Wansum Tail. Once I know what kind of body they want, I can make myself over. I can be an Apache NDN who scalps cowboys on the frontier, even though truthfully, I'm Oji-Cree. (Whitehead 2018: 25).

Performing sexuality is here tightly tied to performing ethnicity. The fantasies that white men project on a queer Indigenous body reveal the desire to secure invader masculinity. However, Jonny's conscious decision to perform them shifts the balance of power and allows him to exploit his clients' lust for financial profit.

Due to the exotic stereotyping and sexualization of queer Indigenous bodies, Jonny is initially hesitant towards his sexual leanings and is afraid to engage for the first time in intercourse with an unknown white man. The protagonist imagines the man he flirts with as a monstrous wendigo figure ${ }^{4} . \mathrm{He}$ recounts: "Suddenly I got scared. His body no longer read timid and his red eyes reminded me of the stories of the wendigo my kokum used to tell me when I was bad" (Whitehead 2018: 16). Hence, non-heteronormative desire provokes a sense of fear in the protagonist since homosexual love has negative connotations. Heteronormative pressures urged by both the dominant society and the Indigenous community on reserves influence Jonny's associations of queer sexuality with monstrosity as it transgresses the established norms. At the same time, the fact that his prospective lover is white provides a fear of exploitation. Sugars notices that the figure of wendigo "has also been widely used as a metaphor for the violence of imperialism and the sickness at the heart of the modern capitalist world" (Sugars 2004: 79). Thus, a white homosexual partner might be associated with moral corruption. Even though the reader does not get acquainted with the real motivation of Jonny's one-night-stand sexual partner, who, indeed, might have taken advantage of the young Indigenous gay man, some of the concerns with the sexual act itself are projected by the protagonist as a result of the stigmatization of queerness that he has witnessed earlier in his life.

However, contrary to Jonny's expectations, his first homosexual encounter provides him with a genuine source of empowerment. He and his nameless sexual

4 Wendigo is a cannibal figure present in some North American Indigenous mythologies, including Cree. The wendigo is associated with aberration, a monstrosity following a transgression of community values and norms. To learn more about wendigo and its role in contemporary Indigenous literature, see Sugars (2004), Branach-Kallas (2013), and Gasztold (2016). 
partner recall traditional Indigenous trickster figures ${ }^{5}$ in that they manifest the ability to transform:

\begin{abstract}
I always wondered how he performed that magic, how he shapeshifted his body in the dark, how his edges poked me but never cut me, how he fit into me like a nipple fits into a baby's mouth, how I could read him upside down. His transforming body wrapped around me, blanketed me, made me sweat ceremonially. (Whitehead 2018: 17).
\end{abstract}

Moreover, the homosexual bodily relationship between the characters is approached in the novel in terms of a ceremony and medicine. The imagery applied by Whitehead, referring back to Indigenous trickster figures and the sweat lodge ceremony, locates queer love within the realm of the traditional and provides a sense of continuation of Two-Spirit identities. Further, the sexual encounters that Jonny shares with his lover, Tias, constitute a powerful celebration of eroticism saturated with healing potential as their bodies symbolically merge into one; their bodies "laced" and their "long wet hair coming together like sweetgrass" (Whitehead 2018: 27). June Scudeler (2011) approaches Two-Spirit writing as maskihkiy - medicine "that heals writer, readers, and communities" (Whitehead 2018: 190). Here the merging of TwoSpirit eroticism and mythical trickster realms heals Indigenous queer bodies, producing a sense of reconciliation. Gerald Vizenor stresses this function of trickster poetics, writing that it "does no less in literature to heal and balance the world" (Vizenor 1993: 203). Jonny also asserts the trickster persona while at work: "that excites me. I have so much power when I transform - all that power over blood, veins, and nerve endings" (Whitehead 2018: 26). The trickster shapeshifting character gives the protagonist a sense of control and freedom. The quasi-animalistic, instinctive, unrestrained desire expressed by the trickster figure emerges in Jonny Appleseed as a way of liberation and celebration of the Indigenous queer body.

In Whithead's novel, the body is also represented beyond trickster transformative qualities. The bodies of queer lovers become maps in Jonny and Tias's sexual encounters, as the protagonist recounts: "We watched each other undress, but our bodies were nothing new, no need to compare them because those geographies had already been explored" (Whitehead 2018: 72-73). Corporeal territories mark the sense of the familiar, shifting the balance of power

$5 \quad$ Trickster figures are characters in North American Indigenous mythologies. In different First Nation cultures they are represented by specific animals that are able to shapeshift. Their actions are often based on instincts, sexual drive, selfish motives, thirst, and greed. They possess a creative power in that they can introduce both harmony and chaos. To further explore trickster figures and their significance in Indigenous literatures, see Shackelton (2007) and Vizenor (1993). 
as queer bodies remain in a perfect harmony that refuses exploitation. Thus, the geographies of the lovers' bodies are ones of mutual reciprocity. Jonny and Tias create a bodily safe space that escapes the precarity that, normally, queer Indigenous bodies would be prone to experience. In the homosexual erotic act, their bodies refuse colonial heteronormative discipline. Moreover, the unison of queer bodies resists spatial and temporal settler categories of Canadian exploration, situating Indigiqueer identities in the continuum pre-dating the colonial contact. The land witnesses Jonny and Tias's erotic exploration. They become an integral element of the landscape, blurring the boundaries between the human and non-human, their bodies inscribed within the land:

\begin{abstract}
Our bodies were tired, legs drained of energy, so we linked arms and filled our bellies with air so that we could float like salmon swimming upstream. We stopped resisting the waves and let the water push us back to the shore, our shoulders and hair moussed with seafoam. When we got back to dry land, our bodies were exhausted. I sat on the sand to catch my breath while Tias ran ahead to look for the towels we had recklessly thrown down. The sun was falling and tinted the sky lavender. Tias left a trail of prints in the sand, some disappearing from the pulse of the waves, others filling with water. I got up and followed the steady path of prints; I found him not too much farther ahead, lying exhausted in the sand. I quietly watched him for a few moments before he noticed me, his forearm glittering in the purple haze, his skin so bronzed that he melded with the sand. I sat down beside him, our naked shoulders rubbing, shaking our hair loose of the water like wet dogs, telling stories. (Whitehead 2018: 28)
\end{abstract}

Whitehead represents bodies immersed in the landscape and maps as the contingency between space and queer erotic. At the same time, the erotic encounter becomes a story that will be symbolically anchored in the landscape. In this sense, the land defines queer love, providing its cartography, and queer erotic (re)defines the land, mapping the Indigenous and Two-Spirit presence. Jonny and Tias's homosexual love maps represent therefore the sovereign erotic - their bodies becoming a source of liberation and thriving. On the contrary, Jonny's other homosexual encounters resemble the process of conquest: "I was like a map of DNA, a living river, you could read my body like a book and pinpoint where you'd been and where you would want to go" (Whitehead 2018: 82). In this context, Jonny's body becomes a conquered space, which recalls the colonists' obsession with a cartography that insists on normative mapping of a territory and equates it with possession (Goeman 2013: 35).

Furthermore, the body emerges as a map designed to tempt and promise pleasure. When Jonny attempts to have an intimate encounter with Tias's girlfriend, Jordan, her body is read by the protagonist as a map: "her body like a ravine with berry bushes around its perimeter, a cedar trail guiding me to the mound" (Whitehead 2018: 159). Jordan's body emerges as a naturally tempting and erotic landscape. 
The sense of temptation is strengthened by the use of plant imagery, including species characteristic for the territories of Manitoba and thus situating the body within its local geographical context. Jordan's body is simultaneously a map disclosing the route to pleasure, and a territory which awaits exploration. During the encounter, however, Jonny gets a nosebleed, and he observes that his face has become a "stained map" (Whitehead 2018: 159). This physiological reaction is loaded with a sense of being tainted and makes Jonny withdraw from the sexual act. The erotic encounter between him and Jordan is compared by Jonny to storytelling (Whitehead 2018: 159) - sharing the most intimate pieces of themselves in order to comprehend the divide between them. They cannot become lovers and, simultaneously, share a common subject of their love. The territories of their bodies continue to bear separate mappings, marked by different experiences of Indigeneity in the settler colonial heteronormative Canada. While their itineraries as a woman and as a queer man differ, they both seem to be victims of the heteropatriarchal norms. Jonny loses the possibility to build a relationship with Tias to his attempt to cover his gay identity, pretending to be a cis man, whereas, for the same reason, Jordan is stranded in the relationship, where her love is not fully requited.

Throughout the novel, Jonny remains in a reciprocal relationship with his ancestral territory. He acknowledges the colonial history that it carries, referring to it as a "treaty land" (Whitehead 2018: 69,71). The descriptions of nature rooted in this land are profoundly erotic:

\footnotetext{
Bees buzz around it, their wings slicing through the air, their bodies velvet smooth in a way that reminds me of how I like to shave my pubes. The buds drip a lavender dew and even the rods are golden and erect. All the land is horny as fuck. The treaty land has awakened and the berries are thick with juice that threatens to burst out of their infant seeds. Butterflies swarm in a patch of sunlight, their wings a collective noise that sounds like crinkling plastic or a consistent, hearty fap. (Whitehead 2018: 69).
}

The imagery focusing on colours, textures, and sounds provokes a myriad of seductive sensations. The land itself is fertile and erotic. Nature as represented by Whitehead can thus be considered in the category of animacy, which as stressed by Mel Chen "has the capacity to rewrite conditions of intimacy, engendering different communalisms and revising biopolitical spheres" (Chen 2012: 3). The representation of the fecundity and vitality of the surrounding ecosystem brings about the restoration of reciprocal ecology that links the human with the nonhuman, stressing affinities between queer erotic, Indigeneity, and the environment.

It seems vital to stress that nature animates Jonny's dreams in a sensual way. Although the land has been exploited by industrialism and extractivism, it seems to still carry the (currently dormant) potential to re-invigorate and transform. In 
his dream, the protagonist indulges in what seems both a sacred and an erotic act with a bear, who is his clan's animal. The fusion of queer body and nature instinctively locates gender fluidity as ordinary, countering discourses that position queerness as something "against nature" (Seymour 2013: 3-4; Stein 2010: 285-286). Hence, quite paradoxically, nature becomes the stage of the liberation and contestation of heteronormativity. This erotically loaded scene culminates in Jonny's merging with the land, as he asserts, "all of this treaty land is filled with me" (Whitehead 2018: 70). The encounter of the human and the non-human offers new potentialities that heal and empower both an Indigiqueer body and the environment. The unison of a queer body and the land, interweaving with the Cree mythological setting, maps alternative geographies, contesting the colonial normative cartography. The spatial poetics applied by Whitehead transgresses the vision of space as solely tied to location, portraying a set of interrelations that enact place and, therefore, show that "space is shifting, layered geographies with connecting and complex histories" (Goeman 2013: 22). It embraces plurality and acknowledges queer Indigenous presence as parallel to the settler colonial situation.

Water emerges as yet another important motif connected to spatiality in Whitehead's novel. Jonny meditates on the significance of water in Cree culture, noting that the name of the Canadian province, Manitoba, comes from a Cree word indicating water (Whitehead 2018: 66). Consequently, bodies of water located on the territory situate the Indigenous community within the net of reciprocal relationships and constitute a part of Aboriginal identity. The reciprocal character of water is also stressed by a non-Indigenous scholar, Astrida Neimanis, in terms of the constant concurrence of the human and the non-human: "the flow and flush of waters sustain our own bodies, but also connect them to other bodies, to other worlds beyond our human selves. Indeed, bodies of water undo the idea that bodies are necessarily or only human" (Neimanis 2017: 2). Hence, aquatic spaces indicate transgression, negotiation, and exchange that, as Neimanis suggests, disrupt notions of individualism, human exceptionalism, and heteropatriarchal, or as she calls them, phallogocentric norms (Neimanis 2017: 3). In the novel, water bears erotic force: "The river is a space of convergence, where streams and currents intersect briefly, an orgy of kissing streams, a hub of sex and slapping fins" (Whitehead 2018: 66). Whitehead applies what might be called hydro-eroticism in order to reflect on the Two-Spirit condition. According to Chow and Bushman, who introduced the concept, fluctuations of water intersect with gender fluidity. They argue that "Hydro-eroticism homes in on these porous boundaries, varied participations, and sites of sexuality by accepting fluid bodies and identities that subsequently reveal the possibilities for intimate pleasure with and through water" (Chow \& Bushman 2019: 98). 
For Jonny, a human body becomes one with the water that builds it, and itself emerges as an aquatic space. Yet the protagonist also feels ambivalent about water: "The elders used to tell us to humble ourselves to the water (...) But water was always a shameful thing for me: to piss, to sweat, to spit, to ejaculate, to bleed, to cry. How in the hell do we humble ourselves to water when we're so damn humiliated by it?" (Whitehead 2018: 66). Chow and Bushman (2019: 100) emphasize that water might be connected to violence against and punishment of queer bodies. Jonny associates bodily liquids with violence against and repression of queerness. Jonny's peers urinate on him so as to ridicule his sexuality (Whitehead 2018: 97); hence, the liquidity of urine is associated with shame and abuse. Further, Jonny's body bleeds when his stepfather, Roger, beats him with a belt for dancing with another boy (Whitehead 2018: 173-174). Tias's hands bleed, too, when his father punishes him for expressing his non-heteronormativity (Whitehead 2018: 76-77), which again links a bodily liquid, in this case blood, with a punitive action. Bodily liquids permeate the novel's imagery, and their negative concurrence with violence performed by other Indigenous men exposes masculindian discipline within the community and the sense of ubiquitous precarity that Indigiqueer bodies are subjected to.

While water is depicted as humiliating due to the bodily liquids that accompany the protagonist's physiological reactions connected to shame, it also emerges as liberating to queer erotics. It reshapes the body and frames queerness within the context that emphasizes gender fluidity:

\footnotetext{
In the water I was beautiful: my boy body was genderless in the tub, my penis too shrivelled to really look like anything but the nether regions of a Barbie doll, my nipples shielded by a facecloth, covering a shame that would never be mine. The water never set me straight. (Whitehead 2018: 67).
}

The liquidity of water is oftentimes associated with womanhood due to its fluidity and fluctuations, as well as, further, contrasted with stable and static masculinity (Neimanis 2017: 78). In this passage Whitehead reiterates this rhetoric, however, in order to disturb its heteronormative duality, he adds queerness to the equation. In an interview for The Next Chapter Whitehead considers water "a perfect metaphor for how [he] would read Two-Spiritedness" in that it is capable of evening sharp edge spaces and its fluidity allowing it to move "gracefully across the land" (Rogers \& Whitehead 2018). If a queer body and water converge, then again the human emerges as spatialized and engages in a complex relationship with the non-human. Being themselves water bodies, human beings are a part of the landscape. Water becomes a space for Tias and Jonny to explore and, subsequently, express their queer love: 


\begin{abstract}
He carried me out in the water as far as we could still stand, the shore drifting farther and farther, the water throwing our laughs back at us. When Tias was finally exhausted, he let go of me, and we stood there, looking at one another, the waves throwing us back to the shore (Whitehead 2018: 27-28).
\end{abstract}

Queer erotics also revitalize the environment and reclaim Indigenous geography. Although during the colonial process some of these geographies were meant to be eradicated, they still prevail and have the potentiality to thrive, which is emphasized in the novel by the celebration of Indigiqueer love and hydro-eroticism. The alternative cartography surfacing from the meeting of queer bodies and water, as well as the erotic undertone of this encounter, maps in Whitehead's novel the poetics of sovereign erotic, where "non-normative scenes of desire and pleasure can provide insight into the mechanisms of settler imperialism and the possibilities for forms of collective identification displaced and foreclosed by state logics" (Rifkin 2011: 186).

Indeed, Indigiqueer love emerges in Whitehead's novel as a source of resistance. Even though settler colonial order, imposing practices and policies disciplining Two-Spirit bodies, has not envisioned that queer Indigenous persons would continue to exist, the representation of queer Indigenous intimacy and desire offered in Jonny Appleseed transgresses colonial gendercide aspirations and refuses heteropatriarchal impositions. The celebration of queer sexuality clearly provides a sense of contestation and liberation from heteronormative social expectations. Whitehead's narrative directs the reader's attention to the fact that accommodating Two-Spirit individuals within their communities is a work towards a more inclusive Aboriginal sense of belonging that has the potential to unsettle colonial structures. Hence, the inclusion of Two-Spirit identities emerges as an essential part of the decolonial struggle in Canada. Further, environmental entanglements evoke a new ecology that revitalizes the ecosystems and queer Indigenous bodies contested under settler colonialism. Sovereign erotic staged within nature symbolically heals both Indigenous communities and the environment. The water and nature imagery, intersecting with erotic desire present in Whitehead's narrative, also stresses the potential of sovereign erotic to transcend not only the colonial gender regime, but also settler colonial normative mappings. By eroticizing space and converging it with passionate queer love, the novel proposes an alternative geography based on reciprocity of the human and the nonhuman. In this way, Whitehead's protagonist functions as an embodied sovereign map. Such a representation provides room for the subversion of established colonial cartography since, as stated by Goeman, "Alternative conceptions of borders, nations, and place are subversive to the masculine project of empire building" (Goeman 2013: 29). Hence, Jonny's queer intimacy merging with the land shifts the power balance, symbolically restoring the Indigenous connection and legitimacy to ancestral territories, unmapping settler geographical impositions. 


\section{REFERENCES}

Anderson, Kim, John Swift \& Robert A. Innes. 2015. 'To arrive speaking': Voices from the Bidwewidam Indigenous Masculinities Project. In Robert A. Innes \& Kim Anderson (eds), Indigenous men and masculinities: Legacies, identities, regeneration, University of Manitoba Press. 283-307.

Belcourt, Billy-Ray. 2017. Meditations on reserve life, biosociality, and the taste of nonsovereignty. Settler Colonial Studies 8(1). 1-15. DOI: 10.1080/2201473X.2017.1279830

Belcourt, Billy-Ray \& Lindsay Nixon. 2018. What do we mean by queer Indigenous ethics? https://canadianart.ca/features/what-do-we-mean-by-queerindigenousethics/ (accessed 21/09/2019)

Branach-Kallas, Anna. 2013. Gothicizing the Wendigo: The ambivalences of monstrosity in Three Day Road by Joseph Boyden. In Ryszard W. Wolny \& Zdzisław Wąsik (eds), Faces and masks of ugliness in literary narratives, Peter Lang. 45-55.

Chen, Mel Y. 2012. Animacies: Biopolitics, racial mattering, and queer affect. Duke University Press.

Chow, Jeremy \& Brandi Bushman. 2019. Hydro-eroticism. English Language Notes 57(1). 96-115.

Driskill, Qwo-Li. 2004. Stolen from our bodies: First Nations Two-Spirits/queers and the journey to a sovereign erotic. Studies in American Indian Literatures 16(2). 50-64.

Driskill, Qwo-Li, Chris Finley, Brian J. Gilley \& Scott L. Morgensen. 2011. Introduction. In QwoLi Driskill, Chris Finley, Brian J. Gilley \& Scott L. Morgensen (eds), Queer Indigenous studies: Critical interventions in theory, politics, and literature, The University of Arizona Press. 1-28.

Driskill, Qwo-Li, Daniel H. Justice, Deborah Miranda \& Lisa Tatonetti. 2012. Introduction: Writing in the present. In Qwo-Li Driskill, Daniel H. Justice, Deborah Miranda \& Lisa Tatonetti (eds), Sovereign erotics: A collection of Two-Spirit literature, The University of Arizona Press. 1-17.

Finley, Chris. 2011. Decolonizing the queer Native body (and recovering the Native bull-dyke): bringing "sexy" back and out of Native studies' closet. In Qwo-Li Driskill, Chris Finley, Brian J. Gilley \& Scott L. Morgensen (eds), Queer Indigenous studies: Critical interventions in theory, politics, and literature, The University of Arizona Press. 31-42.

Gasztold, Brygida. 2016. Reclamation, redress, and remembrance: Aboriginal soldiers of the Great War in Joseph Boyden's Three Day Road. Transcanadiana 8. 81-101.

Goeman, Mishuana. 2013. Mark my words: Native women mapping our nations. University of Minnesota Press.

Hokowithu, Brendan. 2015. Taxonomies of indigeneity: Indigenous heterosexual patriarchal masculinity. In Robert A. Innes \& Kim Anderson (eds), Indigenous men and masculinities: Legacies, identities, regeneration, University of Manitoba Press. 80-95.

Jacobs, Sue-Ellen. 1968. Berdache: A brief review of the literature. Colorado Anthropologist 1(1). 2540.

Jacobs, Sue-Ellen, Wesley Thomas \& Sabine Lang (eds). 1997. Two-Spirit people: Native American gender identity, sexuality, and spirituality. University of Illinois Press.

Justice, Daniel H. 2008. Fear of a changeling moon: A rather queer tale from a Cherokee hillbilly. In Drew H. Taylor (ed.), Me sexy:An exploration of Native sex and sexuality, Douglas \& McIntyre. 61-73. 
McKegney, Sam. 2014. Masculindians: Conversations about Indigenous manhood. University of Manitoba Press.

McLeod, Neal. 2001. Coming home through stories. In Armand G. Ruffo (ed.), (Ad)dressing our words: Aboriginal perspectives on Aboriginal literatures, Theytus Book Ltd. 17-36.

Medicine, Beatrice. 1997. Changing Native American roles in an urban context and changing Native American sex roles in an urban context. In Sue-Ellen Jacobs, Wesley Thomas \& Sabine Lang (eds), Two-Spirit people: Native American gender identity, sexuality, and spirituality, University of Illinois Press. 145-155.

Miranda, Deborah A. 2010. Extermination of the Joyas: Gendercide in Spanish California. GLQ: A Journal of Lesbian and Gay Studies 16(1-2). 253-284.

Morgensen, Scott L. 2011. Unsettling queer politics: what can non-Natives learn from Two-Spirit organizing? In Qwo-Li Driskill, Chris Finley, Brian J. Gilley \& Scott L. Morgensen (eds), Queer Indigenous studies: Critical interventions in theory, politics, and literature, The University of Arizona Press. 132-152.

Neimanis, Astrida. 2017. Bodies of water. Posthuman feminist phenomenology. Bloomsbury Academic.

The National Inquiry into Missing and Murdered Indigenous Women and Girls. 2019. Lexicon of terminology/Lexique terminologique. https://www.mmiwg-ffada.ca/wpcontent/uploads/2019/06/MMIWG_Lexicon_FINAL_ENFR.pdf (accessed 05/072020)

Rifkin, Mark. 2011. The erotics of sovereignty. In Qwo-Li Driskill, Chris Finley, Brian J. Gilley \& Scott L. Morgensen (eds), Queer Indigenous studies: Critical interventions in theory, politics, and literature, The University of Arizona Press. 172-189.

Rogers, Shelagh \& Joshua Whitehead. 2018. Why Joshua Whitehead explores being Indigiqueer and two-spirit in his debut novel. The Next Chapter. https://www.cbc.ca/radio/thenextchapter/full-episode-dec-31-2018-1.4956361/whyjoshua-whitehead-explores-being-indigiqueer-and-two-spirit-in-his-debut-novel1.4956994 (accessed 05/08/2020)

Scudeler, June. 2011. Gifts of maskihkiy: Gregory Scofield's Cree Métis stories of self-acceptance. In Qwo-Li Driskill, Chris Finley, Brian J. Gilley \& Scott L. Morgensen (eds), Queer Indigenous studies: Critical interventions in theory, politics, and literature, The University of Arizona Press. 172-189.

Seymour, Nicole. 2013. Strange natures: Futurity, empathy, and the queer ecological imagination. University of Illinois Press.

Shackleton, Mark. 2007. The ever-travelling trickster: the trickster figure in Native and non-Native North American writing. In Hartmut Lutz \& Thomas Rafico Ruiz (eds), What is your place? Indigeneity and immigration in Canada, Wißner-Verlag. 74-82.

Simpson, Leanne Betasamosake. 2017. As we have always done: Indigenous freedom through radical resistance. University of Minnesota Press.

Stein, Rachel. 2010. "The place, promised, that has not yet been": The nature of dislocation and desire in Adrienne Rich's Your Native Land/ Your Life and Minnie Bruce Pratt's Crime Against Nature. In Catriona Mortimer-Sandilands \& Bruce Erickson (eds), Queer ecologies: Sex, nature, politics, desire, Indiana University Press. 285-308.

Sugars, Cynthia. 2004. Strategic abjection: Windigo psychosis and the "postindian" subject in Eden Robinson's "Dogs in Winter". Canadian Literature 181. 78-91.

Vizenor, Gerald. 1993. Trickster discourse: Comic holotropes and language games. In Gerald Vizenor (ed.), Narrative chance: Postmodern discourse on Native American Indian literatures, The University of Oklahoma Press. 187-211. 
Vizenor, Gerald. 2009. Native liberty: Natural reason and cultural survivance. University of Nebraska Press.

Whitehead, Joshua. 2018. Jonny Appleseed (Kindle edn). Arsenal Pulp Press.

Whyte, Kyle P. 2017. Our ancestors' dystopia now: Indigenous conservation and the Anthropocene. In Ursula K. Heise, Jon Christensen \& Michelle Niemann (eds), The Routledge companion to the environmental humanities, Routledge. 206-215.

Younging, Gregory. 2018. Elements of Indigenous style: A guide for writing by and about Indigenous Peoples. Brush Education. 